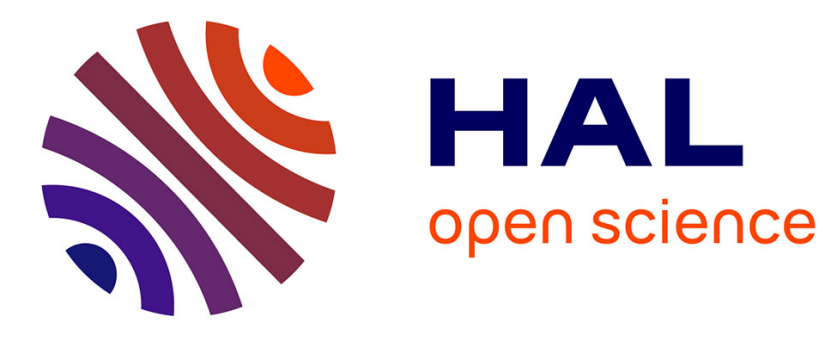

\title{
Self-protection with random costs
}

David Crainich, Mario Menegatti

\section{To cite this version:}

David Crainich, Mario Menegatti. Self-protection with random costs. Insurance: Mathematics and Economics, 2021, 98, pp.63-67. 10.1016/j.insmatheco.2021.02.006 . hal-03273664

\section{HAL Id: hal-03273664 \\ https://hal.science/hal-03273664}

Submitted on 18 Oct 2021

HAL is a multi-disciplinary open access archive for the deposit and dissemination of scientific research documents, whether they are published or not. The documents may come from teaching and research institutions in France or abroad, or from public or private research centers.
L'archive ouverte pluridisciplinaire HAL, est destinée au dépôt et à la diffusion de documents scientifiques de niveau recherche, publiés ou non, émanant des établissements d'enseignement et de recherche français ou étrangers, des laboratoires publics ou privés. 


\title{
Self-protection with random costs
}

\author{
DAVID CRAINICH \\ CNRS, IESEG School of Management, Univ. Lille, UMR 9221 - LEM \\ 3, rue de la Digue \\ 59000 Lille, France \\ d.crainich@ieseg.fr \\ MARIO MENEGATTI \\ Dipartimento di Scienze Economiche e Aziendali \\ Università di Parma \\ via Kennedy 6 \\ 43123 Parma, Italy \\ mario.menegatti@unipr.it
}

October 18, 2021

\begin{abstract}
We study the consequences of introducing random costs (as opposed to certain costs) on the propensity to implement self-protection actions, i.e. actions reducing the probability of a loss. Our analysis is performed in four standard self-protection frameworks: 1) the one-period model in which the cost and benefit occur at the same period of time; 2) a variation of this one-period model where wealth in each state of nature is a random variable; 3 ) the one-period model where the cost of the self-protection action is only paid in the absence of loss; 4) the two-period model in which the cost of self-protection precedes its benefit. For each of these models we provide a set of conditions ensuring clear-cut effects to occur and a specific interpretation for each of them.

JEL Code: D81

Keywords: Self-protection; Random costs of self-protection; Risk aversion; Prudence
\end{abstract}




\section{Introduction}

When facing the risk of incurring a loss a decision maker (henceforth DM) sometimes has the opportunity to exert effort in activities reducing the probability that the loss occurs. The literature on decision theory under risk calls these activities self-protection or prevention and studied them in different frameworks.

The first approach analyzing the issue of self-protection was proposed in the seminal paper by Ehrlich and Becker (1972). In this paper, the cost of effort in self-protection is assumed to be paid in the period where the DM faces the risk of incurring the loss (thus generating a one-period framework) and in both states of nature, i.e. both when the loss occurs and when it does not. A first variation of the framework just described was studied by Jindapon and Neilson (2007) who consider the case where the certain levels of wealth obtained in the two states of nature in Ehrlich and Becker model are replaced by random variables. A different one-period model was then examined by Liu et al. (2009), who consider the case where the cost of exerting the effort in self-protection is paid in the period where the DM faces the risk (one-period framework) but only when there is no loss ("conditional payment"). Lastly Menegatti (2009) suggests that in many cases self-protection activities precede the moment where the DM faces the risk he desires to prevent. For this reason, Menegatti (2009) proposes a two-period model where the cost of the self-protection action and the risk of incurring the loss in wealth occur in different periods.

Many cases of self-protection alternatively described by the four approaches mentioned above can be provided 1 A simple unifying example clearly distinguishing the four models can be the following. An individual has to prepare a contract that might generate in the future controversies, causing a trial and, possibly, the payment of a penalty. The individual can reduce the probability of paying the penalty in different ways which can be referred to the different models described above. The individual can pay a lawyer in the present in order to properly write the contract, thus reducing the probability of trial and the potential payment of the penalty (two-period self-protection framework). Alternatively, the individual can write by himself the contract and pay a lawyer in case of controversy in order to reduce the probability of paying the penalty. In this case the lawyer can charge by the hour (one-period self-protection framework) or offer legal service and then collect a fee only in case of success (one-period self protection framework with conditional payment).$^{2}$ Besides, the individual may also write the contract by himself in a situation where his wealth is random (one-period self-protection framework with random wealth).

The basic self-protection models (of the four kinds described above) has been made more complex by introducing other sources of uncertainty. In particular, Crainich et al.

\footnotetext{
${ }^{1}$ See, for instance, Liu et al. (2009) and Menegatti (2009).

${ }^{2}$ The case of professionals getting a fee only in case of success is exactly that discussed by Liu et al. (2009) in motivating their work.
} 
(2016) re-examine Jindapon and Neilson model considering changes in risk of different orders. A similar framework is studied by Chuang et al. (2013) and Wong (2017), who study models where effort is exerted in the presence of risky targets. Lastly Eeckhoudt et al. (2012) and Wang and Li (2015) analyze the effect of the introduction of a background risk in two-period self-protection framework $3^{3}$

Although other sources of uncertainty have been introduced into the analysis, one of them has been, to our knowledge, neglected until now: the uncertainty on the cost of self-protection. It can happen, in fact, that when choosing the level of effort he will exert in self-protection, the DM does not know exactly the cost he will have to pay for it. Consider again, for instance, the example discussed above of hiring a lawyer: in this case the decision maker often only have ex-ante a quote of the cost of the legal services he is buying, the exact cost he will have to pay being communicated ex-post by the professional. Similarly, consider the risk of an environmental damage whose probability can be reduced by decreasing a specific kind of polluting investment. The cost of such a disinvestment, expressed in terms of reduced economic activity, is only estimated ex-ante, the exact value of the specific multiplier of the investment being observed ex-post. Lastly, consider the case of a DM who wants to reduce the probability of incurring a disease by means of a medical treatment whose cost is represented by side effects. The possible occurrence of these side effects and their strengths cannot be perfectly anticipated ex ante and are exactly known only ex-post. $4^{4}$

The aim of this work is to study the effects of the introduction of a random cost of self-protection on DM's optimal choice in all the four self-protection models described at the beginning of this section. For each model, we highlight and interpret the conditions under which replacing a non-random cost of self-protection by a random cost of equal mean reduces the propensity to perform such self-protection actions.

The paper proceeds as follows. Section 2 provides a general presentation of the assumption of the self-protection model. We then examine the effects of a random cost of effort specifically distinguishing the four frameworks described above (Section 3). Namely: the two-period model (Section 3.1), the one-period model with conditional payment (Section 3.2), the standard one-period model (Section 3.3) and the one-period model with random wealth (Section 3.4). Section 4 concludes.

\section{The self-protection model}

Consider a Decision Maker (DM) who has an initial wealth equal to $W$ and faces the risk of incurring a loss $L$ with probability $p$, i.e. his wealth remains $W$ with probability

\footnotetext{
${ }^{3}$ Other paper studying self-protection which should be mentioned are Chiu et al. (2005), Eeckhoudt and Gollier (2005), Huang (2012), Menegatti (2014) and Huang et al. (2015). On a related issue see also Wang et al. (2015).

${ }^{4}$ On the issue of random side effects of vaccination see also Crainich et al. (2019).
} 
$1-p$ and becomes $W-L$ with probability $p$. We also assume that the DM can exert a costly effort to reduce the probability of incurring the loss. We thus assume that $p$ is a function of the effort $e$ such as $p=p(e)$ and $\frac{d p}{d e}=p^{\prime}(e)<0$. We also introduce the usual assumption that $\frac{d^{2} p}{d e^{2}}=p^{\prime \prime}(e)>0$ which captures the fact that self-protection returns are decreasing. Effort $e$ has a unit cost $c$.

Preferences of the DM are represented by the utility function $U(x)$, which exhibits non-satiation $\left(\frac{\partial U}{\partial x}=U^{\prime}(x)>0\right)$ and risk aversion $\left(\frac{\partial^{2} U}{\partial x^{2}}=U^{\prime \prime}(x)<0\right)$. We also recall the definition of prudence, which is characterized by a positive third derivative of the utility function $\left(\frac{\partial^{3} U}{\partial x^{3}}=U^{\prime \prime \prime}(x)>0\right)$. We do not assume prudence but it will be relevant for the results obtained in the paper.

Given these general assumptions we consider now four different frameworks studied in the literature.

The first framework examined is the two-period model by Menegatti (2009). In this model we assume that the DM exerts effort $e$ in a period preceding that where he faces the risk of incurring the loss $L$. In this case DM's utility in first period is $U\left(W_{0}-c e\right)$ (assuming that $W_{0}$ is first-period wealth) and his expected utility in second-period is $p(e) U(W-L)+[1-p(e)] U(W)$. Assuming for simplicity a null intertemporal discount rate, DM's total intertemporal utility is given by $U\left(W_{0}-c e\right)+p(e) U(W-L)+[1-p(e)] U(W)$.

The second framework considered is the one-period model with conditional payment introduced by Liu et al. (2009). In this model we assume that the DM exerts effort $e$ in the period where he faces the risk of incurring the loss $L$ and we assume that the cost of the effort is paid only if the loss $L$ does not occur. In this context DM's expected utility in the unique period examined is equal to $p(e) U(W-L)+[1-p(e)] U(W-c e)$.

The third framework is the traditional one-period model by Ehrlich and Becker (1972). In this model we assume that the DM exerts effort $e$ in the period where he faces the risk of incurring the loss $L$ and that the cost of the effort is paid in both states of nature, i.e. both when the loss $L$ occurs and when it does not. In this context DM's expected utility in the unique period examined is equal to $p(e) U(W-L-c e)+[1-p(e)] U(W-c e)$.

Lastly a variant of the traditional one-period model is proposed by Jindapon and Neilson (2007) who assume that the DM has a random initial wealth $\tilde{W}_{1}$ and faces the risk to replace it with the random wealth $\tilde{W}_{2}$, where the distribution of $\tilde{W}_{1}$ is preferred by the DM over the distribution of $\tilde{W}_{2}$. In this context DM's expected utility in the unique period examined is equal to $p(e) E\left[U\left(\tilde{W}_{2}-c e\right)\right]+[1-p(e)] E\left[U\left(\tilde{W}_{1}-c e\right)\right]$.

The first three models described above are embedded in the following general framework. Consider the two-argument functions $u(w, k)$ and $v(w, k)$, where $w$ is wealth and $k$ is the cost of self-protection and where we assume $\frac{\partial u}{\partial w}>0, \frac{\partial u}{\partial k}<0, \frac{\partial v}{\partial w}>0, \frac{\partial v}{\partial k}<0$, $\frac{\partial^{2} u}{\partial w^{2}}<0, \frac{\partial^{2} u}{\partial k^{2}}<0, \frac{\partial^{2} v}{\partial w^{2}}<0, \frac{\partial^{2} v}{\partial k^{2}}<0$. We use the following notation: $\frac{\partial^{j+i} u}{\partial w^{j} \partial k^{i}}=u^{(j, i)}$ and $\frac{\partial^{j+i} v}{\partial w^{j} \partial k^{i}}=v^{(j, i)}$.

Assume now that the DM faces the following maximization problem:

$$
\max _{e} V(e)=\max _{e} p(e) u(W-L, c e)+[1-p(e)] v(W, c e)
$$


Given (1) the DM maximization problem of the two-period model is obtained by assuming $u(w, k)=v(w, k)=U\left(W_{0}-k\right)+U(w)$. Similarly the maximization problem of the one-period model with conditional payment is obtained by assuming $u(w, k)=U(w)$ and $v(w, k)=U(w-k)$. Lastly, the maximization problem of the traditional one-period model is obtained by assuming $u(w, k)=v(w, k)=U(w-k)$.

The optimal level of effort $e^{*}$ is determined by the following First-Order Condition (FOC) $:^{5}$

$$
p\left(e^{*}\right) c u^{(0,1)}\left(W-L, c e^{*}\right)+\left[1-p\left(e^{*}\right)\right] c v^{(0,1)}\left(W, c e^{*}\right)-p^{\prime}\left(e^{*}\right)\left[v\left(W, c e^{*}\right)-u\left(W-L, c e^{*}\right)\right]=0
$$

We assume that the second-order condition for the problem is satisfied. This automatically occurs, given the assumptions of the model, in the two-period framework and in the one-period framework with conditional payment. Additional requirements are instead necessary in the traditional one-period framework. For a discussion on this, see Ehrlich and Becker (1972).

Note that the first addend of the left-hand side of (2) is the opposite of the marginal cost of self-protection while the second addend is the marginal benefit. This implies that condition (2) just requires that marginal cost and marginal benefit of self-protection are equal.

Finally, Jindapon and Neilson (2007) model can be obtained as a variant of the general model described in (1) by: 1) replacing $u(W-L, c e)$ by $E\left[u\left(\tilde{W}_{2}, c e\right)\right]$ and $v(W, c e)$ by $\left.E\left[v\left(\tilde{W}_{1}, c e\right)\right] ; 2\right)$ assuming that $u(w, k)=u(w, k)=U(w-k)$. In this framework we obtain a condition similar to (2), given by

$p\left(e^{*}\right) c E\left[u^{(0,1)}\left(\tilde{W}_{2}, c e^{*}\right)\right]+\left[1-p\left(e^{*}\right)\right] c E\left[v^{(0,1)}\left(\tilde{W}_{1}, c e^{*}\right)\right]-p^{\prime}\left(e^{*}\right)\left[E\left[v\left(\tilde{W}_{1}, c e^{*}\right)\right]-E\left[u\left(\tilde{W}_{2}, c e^{*}\right)\right]\right]=0$

The interpretation of this equation is similar to that of Eq. (2) above.

\section{Random cost of self-protection}

We now study the effects of the introduction of a random cost of self-protection. For this purpose we assume that the unit cost of effort in self-protection is the random variable $\tilde{c}$ (with $E[\tilde{c}]=c){ }^{6}$

In this case the DM's maximization problem in Eq. (1) becomes

$$
\max _{e} E[\hat{V}(e)]=\max _{e} p(e) E[u(W-L, \tilde{c} e)]+[1-p(e)] E[v(W, \tilde{c} e)]
$$

${ }^{5} u^{(0,1)}$ and $v^{(0,1)}$ refer to the first derivative of, respectively, the functions $u$ and $v$ with respect to their second attribute.

${ }^{6}$ We emphasize that the assumption $E[\tilde{c}]=c$ is made in order to capture a pure increase in risk. In other words, moving to the case of random cost implies a change in the variability of $c$ but not in its expected value. The introduction of the random cost of self-protection thus corresponds to an increase in risk à la Rotschild and Stiglitz (1970). Also notice that the assumption is necessary for all the results derived hereafter. 
and, labeling the optimal effort chosen in problem (4) $e^{* *}$, the FOC becomes

$$
\begin{gathered}
p\left(e^{* *}\right) E\left[\tilde{c} u^{(0,1)}\left(W-L, \tilde{c} e^{* *}\right)\right]+\left[1-p\left(e^{* *}\right)\right] E\left[\tilde{c} v^{(0,1)}\left(W, \tilde{c} e^{* *}\right)\right] \\
-p^{\prime}\left(e^{* *}\right)\left[E\left[v\left(W, \tilde{c} e^{* *}\right)\right]-E\left[u\left(W-L, \tilde{c} e^{* *}\right)\right]\right]=0(5)
\end{gathered}
$$

We again assume that the second-order condition for the problem is satisfied.

Comparing Eqs. (2) and (5) we now get that $e^{*}>e^{* *}$, if $V^{\prime}\left(e^{* *}\right)>0$, and that $e^{* *}>e^{*}$, if $V^{\prime}\left(e^{* *}\right)<0$.

In order to check this condition we evaluate the left-hand side of (2) for $e=e^{* *}$ obtaining $\left.\left.\left.\left.p\left(e^{* *}\right) c u^{(0,1)}\left(W-L, c e^{* *}\right)\right)+\left[1-p\left(e^{* *}\right)\right)\right] c v^{(0,1)}\left(W, c e^{* *}\right)\right)-p^{\prime}\left(e^{* *}\right)\right)\left[v\left(W, c e^{* *}\right)\right)-$ $\left.\left.u\left(W-L, c e^{* *}\right)\right)\right]$, that we label $h(c)$. By Jensen's inequality, $V^{\prime}\left(e^{* *}\right)>0$ if the function $h(c)$ is concave in $c\left(\frac{d^{2} h}{d c^{2}}=h^{\prime \prime}(c)<0\right)$. Given this result we can now study the effect of a random cost of self-protection in the four models presented in Section 2.

\subsection{Two-period model}

Assume that $u(w, k)=v(w, k)=U\left(W_{0}-k\right)+U(w)$. In this context, which describes the two-period framework, we obtain after straightforward computations

$$
h^{\prime \prime}(c)=2 e^{* *} U^{\prime \prime}\left(W_{0}-c e^{* *}\right)-c e^{* * 2} U^{\prime \prime \prime}\left(W_{0}-c e^{* *}\right)
$$

This immediately determines the following result:

Proposition 1. In case of two-period framework, prudence ( $\left.U^{\prime \prime \prime}()>0.\right)$ is a sufficient condition for the introduction of a zero-mean risk on the cost of effort to generate a reduction in self-protection $\left(e^{*}>e^{* *}\right)$.

As it will also be shown from the comparison between this and next subsections, the two-period self-protection model is the framework where the effects of the introduction of a random unit cost of effort are simpler. In this framework, in particular, the introduction of a random unit cost of self-protection firstly implies that the DM faces a new risk. Because of risk aversion the DM dislikes it and thus makes less self-protection efforts in order to reduce his exposure to this new risk. This is the effect described by the first term in (6). Moreover, the effect of the introduction of the random unit cost $\tilde{c}$ also depends on the attitude toward the intertemporal allocation of wealth and risk. In this field, Menegatti (2007) showed that, in an intertemporal framework, prudence can be seen as the desire to transfer wealth toward the period where the decision maker bears a risk. This conclusion clearly provides an interpretation for the second term in (6) and thus for the role of prudence shown in Proposition 1. The introduction of a random unit cost of self-protection means introducing a new risk in first period. Given this, prudence implies the DM desires to increase first-period wealth by reducing the effort in self-protection.

This explanation is also a direct consequence of the interpretation of preferences toward risk provided by Eeckhoudt and Schlesinger (2006). Introducing a random unit cost $\tilde{c}$ 
instead of $c$ does not modify the marginal benefit of self-protection (which occurs in the second period) but is such that each effort has two effects on the marginal cost of selfprotection (which is paid in the first period): 1) it increases the dispersion of the total cost of self-protection (which is disliked by a risk averse DM); 2) it transfers the risk associated to the random unit cost of self-protection to lower wealth levels (which is disliked by a prudent DM). So that a random unit cost $\tilde{c}$ increases the marginal cost of self-protection and pushes the prudent DM to reduce his effort.

\subsection{One-period model with conditional payment}

Consider the case where $u(w, k)=U(w)$ and $v(w, k)=U(w-k)$, which describes the oneperiod model with conditional payment. After straightforward computations we obtain that

$$
\left.h^{\prime \prime}(c)=\left[-p^{\prime}\left(e^{* *}\right) e^{* *}+2\left[1-p\left(e^{* *}\right)\right]\right] e^{* *} U^{\prime \prime}\left(W-c e^{* *}\right)\right]-c\left[1-p\left(e^{* *}\right)\right] e^{* * 2} U^{\prime \prime \prime}\left(W-c e^{* *}\right)
$$

This immediately determines the following result:

Proposition 2. In case of one-period framework with contingent payment, prudence $\left(U^{\prime \prime \prime}()>0.\right)$ is a sufficient condition for the introduction of a zero-mean risk on the cost of effort to generate a reduction in self-protection $\left(e^{*}>e^{* *}\right)$.

Moving from the two-period self-protection model studied in Subsection 3.1 to the one-period framework with conditional payment, we see that both effects described for the two-period model are still at work. In particular, the effect of the desire to reduce the exposure to the risk on the unit cost of self-protection is the same as that described above. The effect of the allocation of wealth and risk is here related to the allocation between states of nature instead of the intertemporal allocation between periods. In this sense, Eeckhoudt and Schlesinger (2006) showed that prudence can be seen as the desire to disaggregate the two "harms" of having a lower wealth and bearing a risk in different states of nature. This desire reinforces the incentive to reduce self-protection related to risk exposure. Lastly, in the one-period framework with conditional payment, there is a third effect of the introduction of a random cost of self-protection: the impact of the choice of effort level on the probability of incurring the new risk related to the unit cost of self-protection. In particular, a reduction in self-protection generates an increase in the probability of the occurrence of the state of nature where the DM incurs the loss $L$ and a reduction in the probability of the occurrence of the other state of nature. This fact is completely unfavorable in the presence of a given unit cost of self-protection. It has instead also a partial beneficial effect when the unit cost of self-protection is random. In fact, since in the one-period framework with conditional payment the cost of self-protection is paid only in the state of nature where the DM does not incur the loss, a lower probability that this state of nature occurs also implies a lower exposure to the random unit cost of 
effort. This lower exposure is appreciated by the risk averse DM, generating a further incentive to reduce optimal effort in the presence of a random unit cost of self-protection. This incentive is captured by the term $-p^{\prime}\left(e^{* *}\right) e^{* *} U^{\prime \prime}\left(W-c e^{* *}\right)$ in (7).

As we did before, an interpretation in terms of marginal cost and marginal benefit of self-protection can also be provided. The effects on marginal costs are exactly those described in Subsection 3.1. However, we have now also an effect on the marginal benefit of self-protection. The latter depends on the gap between the outcome in the good state of nature and the outcome in the bad state of nature. The introduction of the random unit cost of self-protection reduces this gap since the random cost is only attached to the good state of nature. This implies that marginal benefit decreases too, generating a further incentive for the DM to reduce self-protection effort.

\subsection{Standard one-period model}

Consider the case where $u(w)=,v(w, k)=U(w-k)$, which describes the standard one-period model with up front payment. After straightforward computations we obtain that

$$
\begin{gathered}
\left.h^{\prime \prime}(c)=\left[2 p\left(e^{* *}\right)+p^{\prime}\left(e^{* *}\right) e^{* *}\right] e^{* *} U^{\prime \prime}\left(W-L-c e^{* *}\right)+\left[2\left[1-p\left(e^{* *}\right)\right]-p^{\prime}\left(e^{* *}\right) e^{* *}\right] e^{* *} U^{\prime \prime}\left(W-c e^{* *}\right)\right]+ \\
-c p\left(e^{* *}\right) e^{* * 2} U^{\prime \prime \prime}\left(W-L-c e^{* *}\right)-c\left[1-p\left(e^{* *}\right)\right] e^{* * 2} U^{\prime \prime \prime}\left(W-c e^{* *}\right)
\end{gathered}
$$

Looking at (8) it is clear that the second addend is negative, the third and the fourth addends are negative under prudence (i.e. when $U(.)^{\prime \prime \prime}>0$ ) and the first addend is negative if

$$
\frac{-p^{\prime}\left(e^{* *}\right) e^{* *}}{p\left(e^{* *}\right)}<2
$$

This determines the following result:

Proposition 3. In case of one-period framework with up front payment, prudence ( $U^{\prime \prime \prime}()>$. $0)$ and an elasticity of probability with respect to the effort in self-protection lower than the threshold $2\left(-\frac{p^{\prime}(e) e}{p(e)}<2\right)$ is a set of sufficient conditions for the introduction of a zero-mean risk on the cost of effort to generate a reduction in self-protection $\left(e^{*}>e^{* *}\right)$.

Result interpretation is more complex in the standard one-period model of self-protection à la Ehrlich and Becker (1972). In this case, the three effects mentioned in Subsection 3.2 are again at work together. The effect of the desire to reduce the exposure to the risk on unit cost of self-protection and the effect of the allocation of wealth and risk act in the same direction as above. On the contrary, the effect of the choice of effort level on the probability of incurring the new risk related to the cost of self-protection acts, in this case, in the opposite direction. In this context, in fact, the risky unit cost of self-protection is paid by the DM in both states of nature. This implies that a larger probability of loss 
occurrence is associated with a situation where the DM incurs the loss together with the random cost. This increase the incentive of the DM to make self-protection in order to avoid this situation.

A sufficient condition to exclude that this counteracting effect overcomes the other two effects, which push the DM to reduce the effort, is to have a sufficiently low sensitivity of the probability $p(e)$ to effort $e$. In this case, in fact, the impact of a reduction in self-protection on the probability of incurring together the loss $L$ and the risky cost of self-protection is small. On the other hand, having a sufficiently low sensitivity of the probability $p(e)$ to effort $e$ means having a sufficiently low elasticity of $p(e)$ with respect to $e$. This is exactly the additional sufficient condition required in Proposition 3.

Again we can also provide an interpretation in terms of marginal cost and marginal benefit of self-protection. The effects on marginal cost are the same as those described in previous sections. But, in this case, the marginal cost is a weighted average of the cost paid in the good state of nature and of the cost paid in the bad state of nature. Since the effect on the latter is larger than that on the former for a prudent $\mathrm{DM}: 7 \mathrm{the}$ higher $p(e)$ the larger the effect of the introduction of the random unit cost on the marginal cost of self-protection. For the same reason, when agents are prudent, the presence of the random unit cost $\tilde{c}$ increases the gap between the outcomes in the good and in the bad state of nature. This raises the marginal benefit of self-protection, and this increment is proportional to $-p^{\prime}(e)$. We have a clear-cut effect on the optimal self-protection level only if the increase in marginal benefit is smaller than the increase in marginal cost. Given the reasoning made above, this occurs when $p(e)$ is sufficiently high and $-p^{\prime}(e)$ is sufficiently low, i.e. when the elasticity of the probability with respect to effort is small.

\subsection{One-period model with random wealth}

Consider the framework described in the last part of Section 2. By introducing a random cost of self-protection $\tilde{c}$ we obtain a FOC similar to (5) given by:

$$
\begin{gathered}
p\left(e^{* *}\right) E\left[\tilde{c} u^{(0,1)}\left(\tilde{W}_{2}, \tilde{c} e^{* *}\right)\right]+\left[1-p\left(e^{* *}\right)\right] E\left[\tilde{c} v^{(0,1)}\left(\tilde{W}_{1}, \tilde{c} e^{* *}\right)\right. \\
-p^{\prime}\left(e^{* *}\right)\left[E\left[v\left(\tilde{W}_{1}, \tilde{c} e^{* *}\right)\right]-E\left[u\left(\tilde{W}_{2}, \tilde{c} e^{* *}\right)\right]\right]=0(10)
\end{gathered}
$$

Similarly to what we did in previous cases, we compare Eqs. (3) and (10). Making steps similar to those made in previous subsections we get that Jensen's Inequality implies that, under the assumption that random variables $\tilde{c}$ and $\tilde{W}_{1}$ are independent and that random variables $\tilde{c}$ and $\tilde{W}_{2}$ are independent too, we have $e^{*}>e^{* *}$ if the function

$$
\left.h^{\prime \prime}(c)=\left[2 p\left(e^{* *}\right)+p^{\prime}\left(e^{* *}\right) e^{* *}\right] e^{* *} E\left[U^{\prime \prime}\left(\tilde{W}_{2}-c e^{* *}\right)\right]+\left[2\left[1-p\left(e^{* *}\right)\right]-p^{\prime}\left(e^{* *}\right) e^{* *}\right] e^{* *} E\left[U^{\prime \prime}\left(\tilde{W}_{1}-c e^{* *}\right)\right]\right]+
$$

\footnotetext{
${ }^{7}$ When agents are prudent $u(w-L-E(\tilde{c}))-E u(w-L-\tilde{c})>u(w-E(\tilde{c}))-E u(w-\tilde{c})$; see Eeckhoudt and Schlesinger (2006).
} 


$$
-c p\left(e^{* *}\right) e^{* * 2} E\left[U^{\prime \prime \prime}\left(\tilde{W}_{2}-c e^{* *}\right)\right]-c\left[1-p\left(e^{* *}\right)\right] e^{* * 2} E\left[U^{\prime \prime \prime}\left(\tilde{W}_{1}-c e^{* *}\right)\right]
$$

is concave. Steps similar to those in Subsection 3.3 now imply that

Proposition 4. In the one-period model with random wealth, under the assumption that the risk on wealth and the risk on the cost of effort are independent, prudence $\left(U^{\prime \prime \prime}()>0.\right)$ and an elasticity of probability with respect to the effort in self-protection lower than the threshold $2\left(-\frac{p^{\prime}(e) e}{p(e)}<2\right)$ is a set of sufficient conditions for the introduction of a zero-mean risk on the cost of effort to generate a reduction in self-protection $\left(e^{*}>e^{* *}\right)$.

Since Jindapon and Neilson (2007) model is a variant of the standard model with up front payment, the conditions obtained in Proposition 4 are the same obtained in Proposition 3 with the addition of the assumption of risk independence. For the same reason, the interpretation of Proposition 4 is the same as that proposed in Section 3.3 for the traditional model with up front payment.

\section{Conclusions}

Random costs are often associated with self-protection decisions. In this paper, we analyze the way the introduction of a random unit cost modifies the propensity to perform actions reducing the probability of adverse events in the expected utility model. This selfprotection decision is examined in four different frameworks: 1) the standard one-period model assuming that the cost of the self-protection action is paid both in the no-loss and loss states (Ehrlich and Becker, 1972); 2) Jindapon and Neilson (2007) one-period framework where wealth in both states of nature is random instead of certain; 3) the one-period model where the cost of the self-protection action is only paid in the no-loss state (Liu et al., 2009); 4) the two-period model where the cost of the self-protection action is paid before the potential realization of the adverse event (Menegatti, 2009).

In the third and fourth frameworks, the randomness of the unit cost of self-protection is shown to reduce the demand for self-protection if the DM is prudent. The same conclusion is reached in the first model if, on the top of the conditions related to individual preferences, an additional sufficient condition is made: the elasticity of the probability function with respect to the self-protection effort must be lower than 2 . The set including the conditions on elasticity and prudence is also sufficient in the second model when the risks on wealth and on the cost of effort are independent. We show that the conditions obtained in the different cases analyzed depend on the interaction between three different effects acting in different ways in the four models examined.

In conclusion, it is worth noting that there is a large experimental support for the assumptions of risk aversion and prudence (see, among others, Deck and Schlesinger, 2010 and 2014, Ebert and Wiesen, 2014 and Noussair, Trautmann and Van de Kuilen, 2014). Therefore, if the probability of the adverse event is not too sensitive to the selfprotection action, we may expect the introduction of random (rather than sure) cost to 
reduce the propensity to perform self-protection actions in all the different frameworks we analyzed.

\section{Acknowledgements}

We thank two anonymous referees for their useful comments and suggestions. Mario Menegatti acknowledges financial support by the Programme FIL-Quota Incentivante of University of Parma and co-sponsored by Fondazione Cariparma.

\section{References}

Chiu, W. Henry. 2005. Degree of Downside Risk Aversion and Self-protection. Insurance: Mathematics and Economics 36, 93-€"101.

Chuang, O-Chia C., Louis Eeckhoudt, Rachel J. Huang, and Larry Y. Tzeng. 2013. Risky Targets and Effort. Insurance: Mathematics and Economics 52, 465- $€$ "468

Crainich, David, Louis Eeckhoudt, and Mario Menegatti. 2016. Changing Risk and Optimal Effort. Journal of Economic Behaviour and Organization 125, 97â€-106.

Crainich, David, Louis Eeckhoudt, and Mario Menegatti. 2019. Vaccination as a trade-off between risks. Italian Economic Review, forthcoming, https://doi.org/10.1007/s40797019-00089-w.

Deck, Charles, Harris Schlesinger. 2014. Consistency of higher order risk preferences. Econometrica 82, 1913-1943.

Deck, C., Schlesinger, H. 2010. Exploring higher order risk effects. Review of Economic Studies 77, 1403-1420.

Ebert, Sebastian, Daniel Wiesen. 2014. Joint measurement of risk aversion, prudence, and temperance. Journal of Risk and Uncertainty 48, 231-252.

Eeckhoudt, Louis, and Christian Gollier. 2005. The Impact of Prudence on Optimal Prevention. Economic Theory 26: 989-€"994.

Eeckhoudt, Louis, Rachel J. Huang, and Larry Y. Tzeng. 2012. Precautionary Effort: A New Look. Journal of Risk and Insurance 79, 585-€"590.

Eeckhoudt, Louis, Schlesinger, Harris, 2006. Putting risk in its proper place. American Economic Review 96, 280-289.

Ehrlich, Isaac, and Gary S. Becker. 1972. Market Insurance,Self-insurance, and Selfprotection. Journal of Political Economy 80: 623-648. 
Huang Yi-Chieh, Larry Y. Tzeng, and Lin Zhao. 2015. Comparative Ambiguity Aversion and Downside Ambiguity Aversion. Insurance: Mathematics and Economics 62, 257e'"269.

Huang, Rachel J. 2012. Ambiguity Aversion, Higher-Order Risk Attitude and Optimal Effort. Insurance: Mathematics and Economics, 50, 338-€"345.

Eeckhoudt, Louis, and Harris Schlesinger. 2006. Putting Risk in Its Proper Place. American Economic Review, 96, 280-€'289.

Jindapon, Paan, Neilson, William S. 2007. Higher-order Generalizations of Arrow-Pratt and Ross Risk Aversion: A Comparative Statics Approach Journal of Economic Theory 136, 719-728.

Liu, Liqun, Rettenmaier, Andrew J., Saving Thomas R. 2009 Conditional payments and self-protection Journal of Risk and Uncertainty 38, 159-172.

Menegatti, Mario. 2007. A new interpretation for the precautionary saving motive: a note. Journal of Economics 92, 275-280.

Menegatti, Mario. 2009. Optimal Prevention and Prudence in a Two-Period Model. Mathematical Social Sciences 58, 393â€"397.

Menegatti, Mario. 2014. Optimal Choice on Prevention and Cure: A New Economic Analysis. European Journal of Health Economics 15, 363- $€$ "372.

Noussair, Charles N., Trautmann, Stefan T., Gijs Van de Kuilen, 2014. Higher order risk attitudes, demographics, and financial decisions. Review of Economic Studies 81, $325-355$.

Rothschild, Michal, Joseph E. Stiglitz, 1970. Increasing risk: I. A definition. Journal of Economic Theory 2, 225-243.

Wang, Jiangli, and Jingyuan Li. 2015. Precautionary Effort: Another Trait for Prudence. Journal of Risk and Insurance 82, 977-€"983.

Wang, Hongxia, Jiangli J. Wang, Jingyuan Li, and Xinping Xia. 2015. Precautionary paying for stochastic improvements under background risks. Insurance: Mathematics and Economics 64, 180â€-185.

Wong, Kit Pong. 2017. A note on risky target and effort. Insurance: Mathematics and Economics 73, 27-30. 